\title{
Technical note: Development and validation of a new method for the quantification of soluble and micellar calcium, magnesium, and potassium in milk
}

\author{
M. Franzoi, ${ }^{1}$ G. Niero, M. Penasa, M. Cassandro, and M. De Marchi \\ Department of Agronomy, Food, Natural Resources, Animals and Environment (DAFNAE), University of Padova, Viale dell'Università 16, \\ 35020 Legnaro (PD), Italy
}

\begin{abstract}
Milk mineral content is a key trait for its role in dairy processes such as cheese-making, its use as source of minerals for newborns, and for all traits involving salt-protein interactions. This study investigated a new method for measuring mineral partition between soluble and micellar fractions in bovine milk after rennet coagulation. A new whey dilution step was added to correct the quantification bias due to whey trapped in curd and excluded volume. Moreover, the proposed method allowed the quantification of the diffusible volume after milk coagulation. Milk mineral content and concentration in whey, and diluted whey were quantified by acid digestion and inductively coupled plasma optical emission spectrometry. The repeatability of the method for micellar $\mathrm{Ca}, \mathrm{Mg}$, and $\mathrm{K}$ was between 2.07 and $8.96 \%$, whereas reproducibility ranged from 4.01 to 9.44\%. Recovery of total milk minerals over 3 spiking levels ranged from 92 to $97 \%$. The proposed method provided an accurate estimation of micellar and soluble minerals in milk, and curd diffusible volume.
\end{abstract}

Key words: milk mineral, cheese making, curd, micellar

\section{Technical Note}

Milk has been extensively investigated as source of macro- and micronutrients such as essential minerals. In particular, Ca supply is essential for human health (Caroli et al., 2011; Dror and Allen, 2014; Burckhardt, 2015), growth (Sheikh et al., 1987), and regulation and maintenance of physiological functions (Weaver, 2014). Magnesium intake from dairy food is correlated with insulin sensitivity (Ma et al., 2006), and K is important in physiological functions such as blood pressure control (O'Halloran et al., 2016).

Received June 30, 2017.

Accepted November 1, 2017.

${ }^{1}$ Corresponding author: marco.franzoi@studenti.unipd.it
Besides their effects on health, minerals influence milk technological traits (Tsioulpas et al., 2007) and are crucial for cheese manufacturers in countries such as Italy, as well as several other countries where milk is mainly used for cheese making (Cassandro, 2003; Rosa et al., 2016). Calcium and $\mathrm{Mg}$ are related to casein structure, which is primarily involved in the coagulation process and curd formation (Malacarne et al., 2014; Toffanin et al., 2015; Visentin et al., 2016). Calcium content plays a fundamental role in the ability of milk to produce cheese, and the addition of Ca salts to milk decreases rennet clotting time and increases curd firmness (Landfeld et al., 2002; Guillaume et al., 2004).

Minerals are present in 2 main forms in milk: soluble (or diffusible) and micellar. Soluble minerals are present in a highly dynamic equilibrium between ionic and associate forms, mainly represented by citrate, phosphate, sulfate, and chloride salts (Holt et al., 1981). Micellar Ca can locate both on the surface or inside the casein micelles. Calcium located on the surface helps micelle aggregation during the formation of the paracasein reticulum (Sandra et al., 2012). At the same time, $\mathrm{Ca}$ is present in the internal part of casein micelles as calcium phosphate, also defined as colloidal calcium. Colloidal Ca fraction is essential in the formation and stabilization of casein micelles (Holt et al., 2013; Ingham et al., 2016), and influences milk coagulation ability (Malacarne et al., 2014; Niero et al., 2016).

Currently, different approaches can be used for the separation of aqueous phase milk for the determination of mineral concentration. Dialysis is one of the first proposed methods but has been demonstrated to be strongly affected by osmotic perturbation determined by equilibration with dialysis buffer (White and Davies, 1958; de la Fuente et al., 1996). Ultrafiltration has been effectively used in several studies, despite its tendency to underestimate soluble Ca concentration as a consequence of $\mathrm{Ca}$ precipitation during the process (deMan, 1962; Vyas and Tong, 2003). Moreover, UF needs adequate machinery and must be carefully set up. Ultracentrifugation (usually around $80,000 \times g$ ) 
gives good estimation of the amount of soluble minerals with an easy sample preparation and can also be used for poor-coagulating milks (Udabage et al., 2000; Jensen et al., 2012), even if high pressure can promote solubilization of minerals from casein micelles (Huppertz and de Kruif, 2006). Finally, rennet coagulation is used to separate micellar from soluble mineral fractions, with good reproducibility, applying the cheesemaking procedure (Malacarne et al., 2014). Nevertheless, it cannot be used for noncoagulating samples. All reported methods need correction factors to take into account the excluded volume effect. Moreover, values obtained from UF require Donnan potential correction factors (Ohshima and Kondo, 1988), which can be taken from the literature or need to be calculated de novo (deMan, 1962; de la Fuente et al., 1996). The present study aimed to develop a new method, based on rennet coagulation, for the determination of soluble and micellar mineral fractions in bovine milk and for overcoming the need of correction factors. In particular, a dilution step was introduced during sample preparation, followed by an hour incubation to allow the complete mineral equilibration between the whey trapped in the paracasein reticulum and the diluted whey. Such a step, with an adequate mathematical transformation, allowed the quantification of the absolute amount of soluble minerals and avoided technical issues due to whey trapped in the curd and excluded volume, which affect the determination of mineral concentration.

Ultrapure water was produced with Arium 611 UV (Sartorius, Monza Brianza, Italy), and all chemicals, if the supplier is not mentioned, were bought from SigmaAldrich (St. Louis, MO) at the highest available purity. Bulk whole raw milk was collected directly by a fluid milk farm distributor (Legnaro, Italy) in March 2017. Milk was analyzed using Milkoscan FT2 (Foss Electronic A/S, Hillerød, Denmark) for major components, resulting in $3.92 \%, 3.60 \%, 2.75 \%, 4.73 \%$, and 6.60 for fat, protein, casein, lactose, and $\mathrm{pH}$, respectively. The milk sample was split in five 100-mL aliquots and processed in less than $3 \mathrm{~h}$ without preservative. Ten milliliters of milk was preheated to $38^{\circ} \mathrm{C}$ for $25 \mathrm{~min}$, added to calf rennet 1:3,000 wt/wt (80\% chimosin, $20 \%$ pepsin, and strength 1:10,000; Clerici-Sacco Group, Cadorago, Italy), and incubated for $30 \mathrm{~min}$ at $36^{\circ} \mathrm{C}$ in a water bath. The curd was cut in the tube in 4 pieces using a round-shaped knife and further incubated for $30 \mathrm{~min}$ at $36^{\circ} \mathrm{C}$. Samples were centrifuged for $15 \mathrm{~min}$ at $20^{\circ} \mathrm{C}$ and $10,000 \times \mathrm{g}$, and $5 \mathrm{~mL}$ of whey was carefully collected. Five milliliters of ultrapure water was added to the remaining curd, vortexed for $20 \mathrm{~s}$, and left 60 min at room temperature for equilibration. The mixture was centrifuged as previously described and $5 \mathrm{~mL}$ of diluted whey was collected. All fractions were stored frozen until inductively coupled plasma optical emission spectrometer (ICP-OES) analysis. A schematic view of sample preparation is depicted in Figure 1. Calcium, $\mathrm{Mg}$, and $\mathrm{K}$ concentrations in samples were determined after digestion using nitric acid in a microwave closed vessel (Ethos 1600 Milestone S.r.l., Sorisole, Italy) as reported in Visentin et al. (2016) and Manuelian et al. (2017). Briefly, ICP-OES Ciros Vision EOP (Spectro Analytical Instruments GmbH, Kleve, Germany) was used for determination of $\mathrm{Ca}$ at $317.933 \mathrm{~nm}, \mathrm{Mg}$ at $285.213 \mathrm{~nm}$, and $\mathrm{K}$ at $766.941 \mathrm{~nm}$ after proper dilution. Calibrations for single minerals were prepared in a range between 0 and $100 \mathrm{mg} / \mathrm{L}$ using single-element solutions (Inorganic Ventures, Christiansburg, VA). Mineral concentrations in whey $\left(\mathbf{C}_{\mathrm{w}}\right)$ and diluted whey $\left(\mathbf{C}_{\mathbf{d}}\right)$ were calculated as

$$
\begin{gathered}
\mathrm{C}_{\mathrm{w}}=\mathrm{M}_{\mathrm{w}} / \mathrm{V}_{\mathrm{w}}, \\
\mathrm{C}_{\mathrm{d}}=\mathrm{M}_{\mathrm{d}} / \mathrm{V}_{\mathrm{d}},
\end{gathered}
$$

where $\mathrm{M}_{\mathrm{w}}$ is the absolute amount of mineral in whey, $\mathrm{V}_{\mathrm{w}}$ is the volume of the whey, $M_{d}$ is the absolute amount of mineral in diluted whey, and $\mathrm{V}_{\mathrm{d}}$ is the volume of diluted whey. According to the experimental design of the present study, $V_{d}$ was equal to $V_{w}$. The $M_{d}$ can be expressed in function of $\mathrm{M}_{\mathrm{w}}$ as

$$
\mathrm{M}_{\mathrm{d}}=\mathrm{M}_{\mathrm{w}}-\mathrm{D} \times \mathrm{C}_{\mathrm{w}},
$$

with $\mathrm{D}$ being the volume of water added for dilution (i.e., $5 \mathrm{~mL}$ for the present study). Combining [1], [2], and [3]:

$$
\begin{gathered}
\mathrm{M}_{\mathrm{w}} / \mathrm{C}_{\mathrm{w}}=\left(\mathrm{M}_{\mathrm{w}}-\mathrm{DC}_{\mathrm{w}}\right) / \mathrm{C}_{\mathrm{d}}, \\
\mathrm{M}_{\mathrm{w}}=\left(\mathrm{DC}_{\mathrm{w}}{ }^{2}\right) /\left(\mathrm{C}_{\mathrm{w}}-\mathrm{C}_{\mathrm{d}}\right),
\end{gathered}
$$

with $\mathrm{C}_{\mathrm{w}}$ and $\mathrm{C}_{\mathrm{d}}$ obtained from ICP-OES. The $\mathrm{V}_{\mathrm{w}}$ was then calculated from [1]. The amount of micellar mineral was expressed as

$$
\mathrm{M}_{\mathrm{c}}=\mathrm{M}_{\mathrm{t}}-\mathrm{M}_{\mathrm{w}},
$$

where $\mathrm{M}_{\mathrm{c}}$ is the amount of micellar mineral expressed in milligrams and $\mathrm{M}_{\mathrm{t}}$ is the total minerals in starting milk from ICP-OES analysis. Final mineral concentrations were expressed as $\mathrm{mg} / 100 \mathrm{~mL}$ of initial milk volume. Repeatability was expressed as relative standard deviation $\left(\mathbf{R S D}_{\mathbf{r}}\right)$ of 5 aliquots from the same bulk milk, processed separately. Reproducibility was calculated as relative standard deviation $\left(\mathbf{R S D}_{\mathbf{R}}\right)$ of 15 samples measured across 3 d (Niero et al., 2017). 
Average recoveries and their $\mathrm{RSD}_{\mathrm{r}}$ were expressed as the ratio between measured and predicted values. Diffusible volume, defined as the volume occupied by all the chemical species not bound to paracasein reticulum such as water, soluble salts, and soluble proteins, was calculated across all the 3 mineral determinations. The amounts of such chemical species in whey and diluted whey were 6.81 and $2.47 \%$, respectively. Diffusible volumes of $\mathrm{RSD}_{\mathrm{r}}$ and $\mathrm{RSD}_{\mathrm{R}}$ were calculated as previously reported across the 3 determined minerals. The Horwitz $\mathrm{RSD}_{\mathrm{R}}(\%)$ and Horwitz ratio (HorRat) were used as comparison for reproducibility (Horwitz and Albert, 2006). The Horwitz value is the expected RSD in reproducibility conditions, and HorRat is the ratio between the experimental and the expected $\mathrm{RSD}_{\mathrm{R}}$.

Compared with previous protocols, the additional dilution step and proposed mathematical transformation permitted the calculation of the total amount of soluble minerals instead of the concentration in whey. The obtained absolute values of soluble minerals are not biased by excluded volume and trapped whey in curd, due to the correction given by the dilution step. For this reason, the calculated values can be directly related to the total amount of mineral in milk to calculate the micellar amount.

On the other hand, the estimation of diffusible volume takes into account both water and solutes, essentially lactose and proteins. To correctly estimate solvent diffusible volume, an excluded volume correction factor would be necessary (Holt, 2004). At the same time, water tightly bound to paracasein reticulum is excluded, consisting of about $2.5 \mathrm{~g}$ of water for each gram of casein (Liu et al., 2012). This explains why the values obtained from our quantification were significantly lower than the water fraction in milk (Table 1).

On average, $79 \%$ of $\mathrm{Ca}, 48 \%$ of $\mathrm{Mg}$, and $25 \%$ of $\mathrm{K}$ were in the micellar phase. Such values are in accordance with recent literature, even if the percentage of micellar $\mathrm{K}$ was slightly higher than expected (de la Fuente et al., 1996). Compared with different quantification approaches, such as ultracentrifugation, the method highlighted a lower amount of soluble minerals (Frederiksen et al., 2011; Jensen et al., 2012). As a further check, a time-resolved quantification of minerals was performed in diluted whey to confirm the complete equilibration between whey in curd and diluted whey. Mineral concentration in diluted whey did not show significant variations after 45 min of incubation, excluding an incomplete equilibration between whey trapped in curd and diluted whey (data not shown).

The robustness of the method was assessed using $\mathrm{RSD}_{\mathrm{r}}$ and $\mathrm{RSD}_{\mathrm{R}}$ (Table 1). Micellar quantifications showed a higher standard deviation compared with soluble and total concentrations in milk, being affected by experimental variation of all 3 measured fractions. Such standard deviations are comparable with other methods presented in the literature (de la Fuente et al., 1996; Noël et al., 2008) and HorRat values were in the desirable range $(<1)$ except for micellar $\mathrm{K}$, which was in the acceptable range (between 1 and 2). This differ-
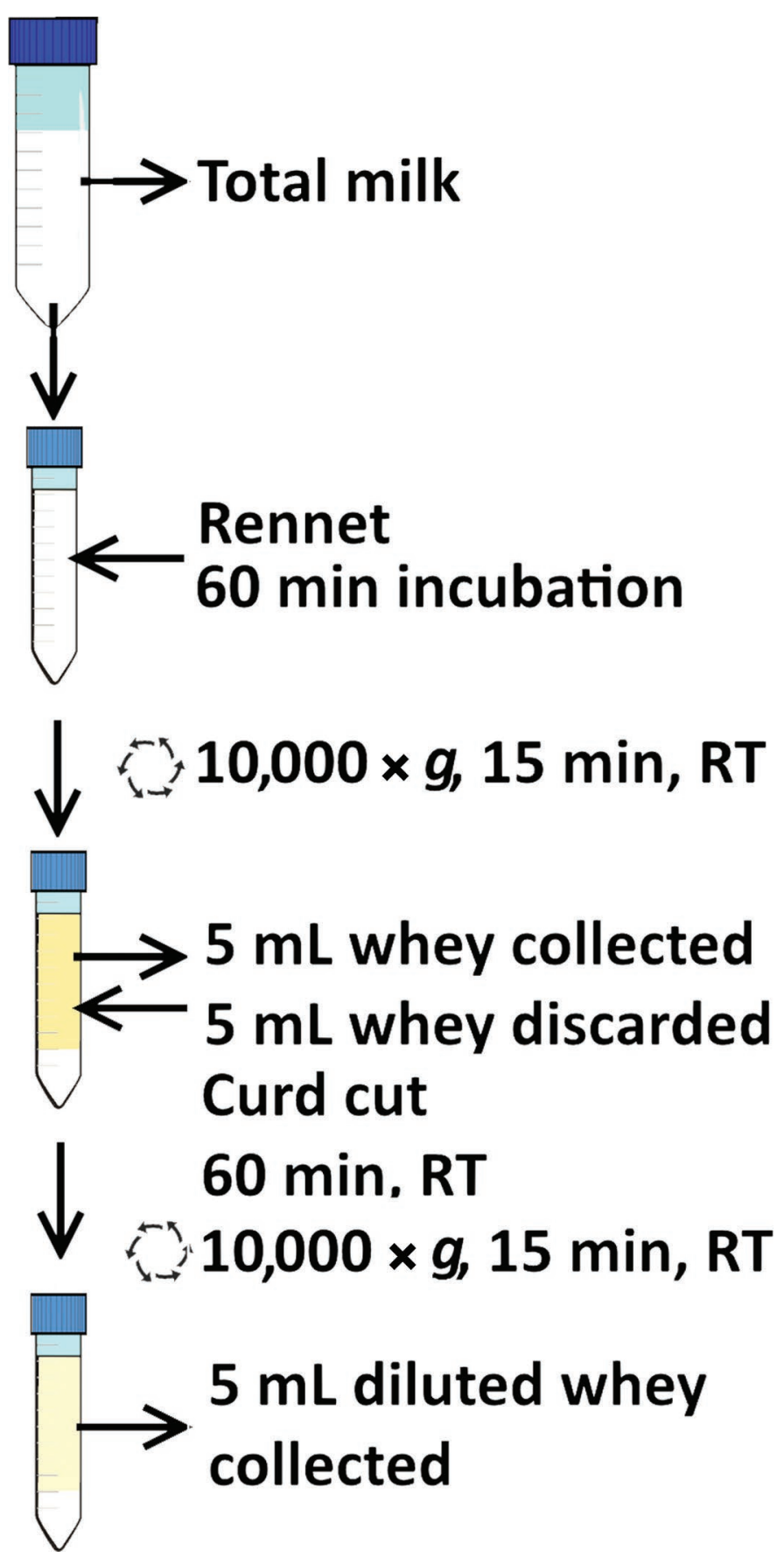

Figure 1. Diagram of sample preparation for the determination of mineral fractions in milk. $\mathrm{RT}=$ room temperature. Color version available online. 
Table 1. Mean, relative standard deviation of repeatability $\left(\mathrm{RSD}_{\mathrm{r}}, \% ; \mathrm{n}=5\right)$, relative standard deviation of reproducibility $\left(\mathrm{RSD} \mathrm{R}_{\mathrm{R}}, \% ; \mathrm{n}=15\right)$, expected Horwitz $\mathrm{RSD}_{\mathrm{R}}(\%)$, and Horwitz ratio (HorRat) for $\mathrm{Ca}, \mathrm{Mg}$, and $\mathrm{K}$ concentrations in milk, and soluble and micellar fractions, and for diffusible volume ${ }^{1}$

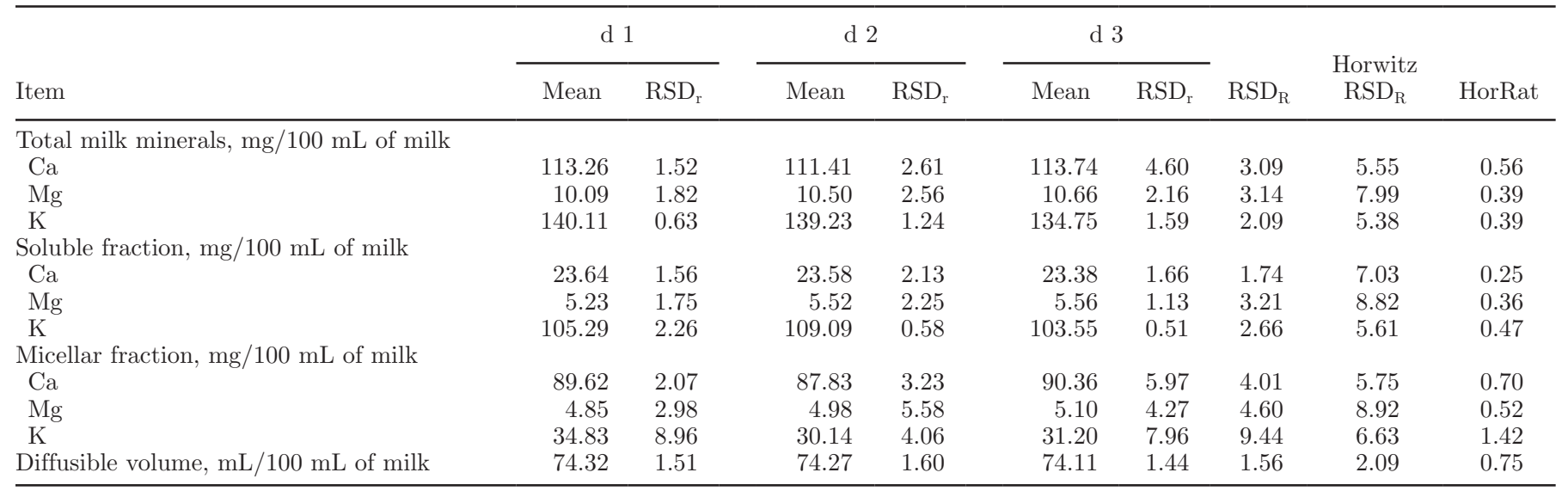

${ }^{1}$ The $\mathrm{RSD}_{\mathrm{r}}$ and $\mathrm{RSD}_{\mathrm{R}}$ of diffusible volume were calculated on $\mathrm{n}=15$ and $\mathrm{n}=45$, respectively.

ence can be related to the relatively high proportion of $\mathrm{K}$ present in the soluble phase. Thus, small variations in whey and diluted whey values resulted in higher variability in micellar quantification.

Recovery of the method was evaluated with a 3-point spiking of the starting milk with a stock solution. The stock solution was prepared by dissolving $1.27 \mathrm{~g}$ of $\mathrm{CaCl}_{2}, 1.17 \mathrm{~g}$ of $\mathrm{KCl}$, and $0.33 \mathrm{~g}$ of $\mathrm{MgCl}_{2}$ in $10 \mathrm{~mL}$ of ultrapure water. One, 2 , or $3 \mathrm{~mL}$ of the stock solution was added to 3 different $100-\mathrm{mL}$ aliquots of milk, thus obtaining spiking levels of 1,2 , and 3 , respectively. Milk $\mathrm{pH}$ was carefully brought back to original values using $1 \mathrm{M} \mathrm{NaOH}$. The aliquots were mixed and split in 5 sub-aliquots and processed separately as previously described. Total milk recovery was in the range 0.92 to 0.97 for all the tests (Table 2). At the same time, even if all the minerals were added as soluble salts, a fraction of them appeared to segregate with the micellar phase. This was particularly true for $\mathrm{Ca}$, which is known to bridge between casein micelles and is used as an additive for improving rheological properties of milk (Philippe et al., 2003; Sandra et al., 2012). Diffusible volumes of spiked samples were slightly higher compared with starting milk, between 75.48 and $80.95 \mathrm{~mL}$ (Table 2). This was somehow expected considering that mineral addition reduced nondiffusible water bound to casein (Philippe et al., 2003).

Most of the methods proposed for soluble mineral quantification are based on concentrations in whey. Considering the whey trapped in the curd and the presence of co-solutes, the conversion to the concentration of soluble minerals in the starting milk is obtained using correction factors. Moreover, for methods based on UF, Donnan potential must be taken into account. Cor-

Table 2. Recovery and relative standard deviation of repeatability $\left(\mathrm{RSD}_{\mathrm{r}}, \% ; \mathrm{n}=5\right)$ for $\mathrm{Ca}, \mathrm{Mg}$, and $\mathrm{K}$ concentrations in milk, and soluble and micellar fractions, and diffusible volume

\begin{tabular}{|c|c|c|c|c|c|c|}
\hline \multirow[b]{2}{*}{ Item } & \multicolumn{2}{|c|}{ Spike level 1} & \multicolumn{2}{|c|}{ Spike level 2} & \multicolumn{2}{|c|}{ Spike level 3} \\
\hline & Mean & $\mathrm{RSD}_{\mathrm{r}}$ & Mean & $\mathrm{RSD}_{\mathrm{r}}$ & Mean & $\mathrm{RSD}_{\mathrm{r}}$ \\
\hline \multicolumn{7}{|c|}{ Total milk mineral recovery, wt/wt } \\
\hline $\mathrm{Ca}$ & 0.97 & 0.73 & 0.95 & 3.34 & 0.96 & 1.03 \\
\hline $\mathrm{Mg}$ & 0.96 & 0.71 & 0.95 & 4.44 & 0.96 & 1.95 \\
\hline $\mathrm{K}$ & 0.96 & 0.80 & 0.92 & 1.55 & 0.94 & 2.95 \\
\hline \multicolumn{7}{|c|}{ Soluble fraction recovery, wt/wt } \\
\hline $\mathrm{Ca}$ & 0.77 & 1.26 & 0.82 & 3.69 & 0.85 & 1.18 \\
\hline $\mathrm{Mg}$ & 1.11 & 1.30 & 1.18 & 3.95 & 1.07 & 1.12 \\
\hline $\mathrm{K}$ & 1.07 & 0.90 & 1.13 & 1.89 & 1.12 & 1.19 \\
\hline \multicolumn{7}{|c|}{ Micellar fraction recovery, wt/wt } \\
\hline $\mathrm{Ca}$ & 1.13 & 1.25 & 1.22 & 4.37 & 1.28 & 2.64 \\
\hline $\mathrm{Mg}$ & 0.86 & 3.12 & 0.96 & 9.77 & 1.17 & 6.24 \\
\hline $\mathrm{K}$ & 0.89 & 4.50 & 0.97 & 8.80 & 1.11 & 4.57 \\
\hline Diffusible volume, $\mathrm{mL}$ & 80.95 & 2.87 & 78.83 & 3.70 & 75.48 & 1.34 \\
\hline
\end{tabular}

${ }^{1}$ The $\mathrm{RSD}_{\mathrm{r}}$ of diffusible volume was calculated on $\mathrm{n}=15$. 
rection factors can be obtained from literature (White and Davies, 1958; Gaucheron, 2005) or measured before the analysis and applied to the samples (de la Fuente et al., 1996). In the first case, issues can arise from historical (Bijl et al., 2013) and seasonal and local variations in milk composition. In the second case, the determination is tedious and irrespective of the sample variability, being calculated on single samples or a subset. The proposed method overcame such biases, giving an accurate estimation of total soluble minerals without the application of correction factors, thanks to a double-step quantification in whey and diluted whey. The suitability of the proposed approach will also be explored for different milk components. This procedure, combined with the potential of mid-infrared spectroscopy and chemometric analysis (Visentin et al., 2017a,b) to predict soluble and micellar minerals on a large scale, could help the dairy industry to better understand the role of milk minerals in cheese making.

\section{ACKNOWLEDGMENTS}

The authors thank Massimo Malacarne (University of Parma) and Carl Holt (University of Glasgow) for sharing their scientific experience, and Luciano Magro (University of Padova) for technical support in setting up experimental procedures.

\section{REFERENCES}

Bijl, E., H. J. F. van Valenberg, T. Huppertz, and A. C. M. van Hooijdonk. 2013. Protein, casein, and micellar salts in milk: Current content and historical perspectives. J. Dairy Sci. 96:5455-5464. https://doi.org/10.3168/jds.2012-6497.

Burckhardt, P. 2015. Calcium revisited, part III: Effect of dietary calcium on BMD and fracture risk. Bonekey Rep. 4:708. https://doi .org/10.1038/bonekey.2015.77.

Caroli, A., A. Poli, D. Ricotta, G. Banfi, and D. Cocchi. 2011. Invited review: Dairy intake and bone health: A viewpoint from the state of the art. J. Dairy Sci. 94:5249-5262. https://doi.org/10.3168/jds .2011-4578.

Cassandro, M. 2003. Status of milk production and market in Italy. Agric. Conspec. Sci. 68:65-69.

de la Fuente, M. A., J. Fontecha, and M. Juárez. 1996. Partition of main and trace minerals in milk: Effect of ultracentrifugation, rennet coagulation, and dialysis on soluble phase separation. J. Agric. Food Chem. 44:1988-1992. https://doi.org/10.1021/jf9506949.

deMan, J. M. 1962. Measurement of the partition of some milk constituents between the dissolved and colloidal phases. J. Dairy Res. 29:279-283. https://doi.org/10.1017/S0022029900011092.

Dror, D. K., and L. H. Allen. 2014. Dairy product intake in children and adolescents in developed countries: Trends, nutritional contribution, and a review of association with health outcomes. Nutr. Rev. 72:68-81. https://doi.org/10.1111/nure.12078.

Frederiksen, P. D., K. K. Andersen, M. Hammersh øj, H. D. Poulsen, J. Sørensen, M. Bakman, K. B. Qvist, and L. B. Larsen. 2011. Composition and effect of blending of noncoagulating, poorly coagulating, and well-coagulating bovine milk from individual Danish Holstein cows. J. Dairy Sci. 94:4787-4799. https://doi.org/10 $.3168 /$ jds.2011-4343.

Gaucheron, F. 2005. The minerals of milk. Reprod. Nutr. Dev. 45:473483. https://doi.org/10.1051/rnd:2005030.
Guillaume, C., E. Gastaldi, J.-L. Cuq, and S. Marchesseau. 2004. Rennet-induced gelation of calcium and phosphate supplemented skim milk subjected to $\mathrm{CO}_{2}$ treatment. J. Dairy Sci. 87:3209-3216. https://doi.org/10.3168/jds.S0022-0302(04)73456-6.

Holt, C. 2004. An equilibrium thermodynamic model of the sequestration of calcium phosphate by casein micelles and its application to the calculation of the partition of salts in milk. Eur. Biophys. J. 33:421-434. https://doi.org/10.1007/s00249-003-0377-9.

Holt, C., J. A. Carver, H. Ecroyd, and D. C. Thorn. 2013. Invited review: Caseins and the casein micelle: their biological functions, structures, and behavior in foods. J. Dairy Sci. 96:6127-6146. https://doi.org/10.3168/jds.2013-6831.

Holt, C., D. G. Dalgleish, and R. Jenness. 1981. Calculation of the ion equilibria in milk diffusate and comparison with experiment. Anal. Biochem. 113:154-163. https://doi.org/10.1016/0003 -2697(81)90059-2.

Horwitz, W., and R. Albert. 2006. The Horwitz ratio (HorRat): A useful index of method performance with respect to precision. J. AOAC Int. 89:1095-1109.

Huppertz, T., and C. G. de Kruif. 2006. Disruption and reassociation of casein micelles under high pressure: influence of milk serum composition and casein micelle concentration. J. Agric. Food Chem. 54:5903-5909. https://doi.org/10.1021/jf060689c.

Ingham, B., A. Smialowska, G. D. Erlangga, L. Matia-Merino, N. M. Kirby, C. Wang, R. G. Haverkamp, and A. J. Carr. 2016. Revisiting the interpretation of casein micelle SAXS data. Soft Matter 12:6937-6953. https://doi.org/10.1039/c6sm01091a.

Jensen, H. B., N. A. Poulsen, K. K. Andersen, M. Hammershøj, H. D. Poulsen, and L. B. Larsen. 2012. Distinct composition of bovine milk from Jersey and Holstein-Friesian cows with good, poor, or noncoagulation properties as reflected in protein genetic variants and isoforms. J. Dairy Sci. 95:6905-6917. https://doi.org/10.3168/ jds.2012-5675.

Landfeld, A., P. Novotna, and M. Houska. 2002. Influence of the amount of rennet, calcium chloride addition, temperature, and high-pressure treatment on the course of milk coagulation. Czech J. Food Sci. 20:237-244.

Liu, D. Z., D. E. Dunstan, and G. J. O. Martin. 2012. Evaporative concentration of skimmed milk: Effect on casein micelle hydration, composition, and size. Food Chem. 134:1446-1452. https:// doi.org/10.1016/j.foodchem.2012.03.053.

Ma, B., A. B. Lawson, A. D. Liese, R. A. Bell, and E. J. Mayer-Davis. 2006. Dairy, magnesium, and calcium intake in relation to insulin sensitivity: Approaches to modeling a dose-dependent association. Am. J. Epidemiol. 164:449-458. https://doi.org/10.1093/aje/ kwj246.

Malacarne, M., P. Franceschi, P. Formaggioni, S. Sandri, P. Mariani, and A. Summer. 2014. Influence of micellar calcium and phosphorus on rennet coagulation properties of cows milk. J. Dairy Res. 81:129-136. https://doi.org/10.1017/S0022029913000630.

Manuelian, C. L., S. Currò, M. Penasa, M. Cassandro, and M. D. Marchi. 2017. Characterization of major and trace minerals, fatty acid composition, and cholesterol content of Protected Designation of Origin cheeses. J. Dairy Sci. 100:3384-3395. https://doi.org/10 .3168/jds.2016-12059.

Niero, G., M. Penasa, S. Currò, A. Masi, A. R. Trentin, M. Cassandro, and M. De Marchi. 2017. Development and validation of a near infrared spectrophotometric method to determine total antioxidant activity of milk. Food Chem. 220:371-376. https://doi.org/10 .1016/j.foodchem.2016.10.024

Niero, G., M. Penasa, P. Gottardo, M. Cassandro, and M. De Marchi. 2016. Short communication: Selecting the most informative mid-infrared spectra wavenumbers to improve the accuracy of prediction models for detailed milk protein content. J. Dairy Sci. 99:1853-1858. https://doi.org/10.3168/jds.2015-10318.

Noël, L., M. Carl, C. Vastel, and T. Guérin. 2008. Determination of sodium, potassium, calcium and magnesium content in milk products by flame atomic absorption spectrometry (FAAS): A joint ISO/IDF collaborative study. Int. Dairy J. 18:899-904. https://doi .org/10.1016/j.idairyj.2008.01.003. 
O'Halloran, S. A., C. A. Grimes, K. E. Lacy, K. J. Campbell, and C. A. Nowson. 2016. Dietary intake and sources of potassium and the relationship to dietary sodium in a sample of Australian pre-school children. Nutrients 8. https://doi.org/10.3390/nu8080496.

Ohshima, H., and T. Kondo. 1988. Membrane potential and Donnan potential. Biophys. Chem. 29:277-281. https://doi.org/10.1016/ 0301-4622(88)85049-X.

Philippe, M., F. Gaucheron, Y. Le Graet, F. Michel, and A. Garem. 2003. Physicochemical characterization of calcium-supplemented skim milk. Lait 83:45-59. https://doi.org/10.1051/lait:2002049.

Rosa, F., R. Weaver, and M. Vasciaveo. 2016. Dairy price commodity in Italy: Volatility and forecast after milk quotas. Proc. Food Syst. Dyn. 112-115. https://doi.org/10.18461/pfsd.2016.1614.

Sandra, S., M. Ho, M. Alexander, and M. Corredig. 2012. Effect of soluble calcium on the renneting properties of casein micelles as measured by rheology and diffusing wave spectroscopy. J. Dairy Sci. 95:75-82. https://doi.org/10.3168/jds.2011-4713.

Sheikh, M. S., C. A. Santa Ana, M. J. Nicar, L. R. Schiller, and J. S. Fordtran. 1987. Gastrointestinal absorption of calcium from milk and calcium salts. N. Engl. J. Med. 317:532-536. https://doi.org/ 10.1056/NEJM198708273170903.

Toffanin, V., M. De Marchi, N. Lopez-Villalobos, and M. Cassandro. 2015. Effectiveness of mid-infrared spectroscopy for prediction of the contents of calcium and phosphorus, and titratable acidity of milk and their relationship with milk quality and coagulation properties. Int. Dairy J. 41:68-73. https://doi.org/10.1016/j idairyj.2014.10.002.

Tsioulpas, A., M. J. Lewis, and A. S. Grandison. 2007. Effect of minerals on casein micelle stability of cows' milk. J. Dairy Res. 74:167173. https://doi.org/10.1017/S0022029906002330.
Udabage, P., I. R. McKinnon, and M. A. Augustin. 2000. Mineral and casein equilibria in milk: Effects of added salts and calciumchelating agents. J. Dairy Res. 67:361-370.

Visentin, G., M. De Marchi, D. P. Berry, A. McDermott, M. A. Fenelon, M. Penasa, and S. McParland. 2017a. Factors associated with milk processing characteristics predicted by mid-infrared spectroscopy in a large database of dairy cows. J. Dairy Sci. 100:32933304. https://doi.org/10.3168/jds.2016-12028.

Visentin, G., S. McParland, M. De Marchi, A. McDermott, M. A Fenelon, M. Penasa, and D. P. Berry. 2017b. Processing characteristics of dairy cow milk are moderately heritable. J. Dairy Sci. 100:6343-6355. https://doi.org/10.3168/jds.2017-12642.

Visentin, G., M. Penasa, P. Gottardo, M. Cassandro, and M. De Marchi. 2016. Predictive ability of mid-infrared spectroscopy for major mineral composition and coagulation traits of bovine milk by using the uninformative variable selection algorithm. J. Dairy Sci. 99:8137-8145. https://doi.org/10.3168/jds.2016-11053.

Vyas, H. K., and P. S. Tong. 2003. Process for calcium retention during skim milk ultrafiltration. J. Dairy Sci. 86:2761-2766. https:// doi.org/10.3168/jds.S0022-0302(03)73872-7.

Weaver, C. M. 2014. How sound is the science behind the dietary recommendations for dairy? Am. J. Clin. Nutr. 99:1217S-1222S https://doi.org/10.3945/ajcn.113.073007.

White, J. C. D., and D. T. Davies. 1958. 712. The relation between the chemical composition of milk and the stability of the caseinate complex: I. General introduction, description of samples, methods and chemical composition of samples. J. Dairy Res. 25:236-255. https://doi.org/10.1017/S0022029900009249. 